\title{
DATABASES AND DISASTERS: A CASE STUDY IN SMALL-N EDUCATIONAL RESEARCH
}

\author{
Thomas Lombardi, University of the Virgin Islands, thomas.lombardi@uvi.edu \\ Matthew North, Utah ValleyUniversity, mnorth@uvu.edu
}

\begin{abstract}
The paper continues previously published research on instructional methods for distance education courses affected by unique and challenging circumstances including technology constraints, time, distance and natural disasters. In this study, we examine the impacts of synchronous, online, and rich media instructional techniques on student learning in a database design and development course. Using backward stepwise elimination and linear regression, we examine environmental and instructional variables to evaluate their impact on student performance on a Structured Query Language (SQL) assessment. We find, somewhat surprisingly, that a live, synchronous session with students through the online video conferencing system Zoom, did not have the desired and positive effect on student learning outcomes that we hypothesized. Possible reasons, including student and instructor unfamiliarity with the platform are discussed. We also find that increased student attention to instructional materials on Blackboard, and increased use of Codecademy.com tutorials and exercises, did produce significant, positive student achievement on the SQL assessment.
\end{abstract}

Keywords: Databases, Distance Education, Information Systems Pedagogy, Small-n research

\section{INTRODUCTION}

Over the past two decades, instructional design and instructional technology research have increasingly examined issues of instructor presence, and more specifically, the potential costs and benefits of online, hybrid, multimedia, and multimodal delivery of educational programs. Our work in this paper blends and enhances prior research, by applying it to an experiment measuring the impacts of synchronous instructional activities and augmented online instructional resources on student achievements in a database course. Born of necessity due to natural disasters, our experiment took place during the Spring 2018 academic semester, following instructional decisions made during the Fall of 2017 under uncertainty driven by catastrophic conditions after two intense hurricanes. A regularly scheduled, multi-site course on database development faced the stark reality that all students could not meet in normal face-to-face sections for instruction, exercise and lecture. Recognizing the reality of damaged and unreliable infrastructure (electricity, Internet), transportation (road and boat routes), and physical facilities (university buildings and equipment), the instructor made the conscientious decision to deliver the course primarily through online delivery, complemented by online multimedia resources and regular synchronous online meetings.

As a result of the aforementioned disruptions, some students in the class were not aware that synchronous instruction would be a part of the class, and subsequently scheduled other classes during the planned synchronous meetings or made other commitments during 'class time'. Thus, all students received the same course content on database development, but not in the same way. Content for the course was delivered via Blackboard, Codecademy, and Zoom, though not all students participated in all three instructional channels. Because students in the course had varied learning experiences as a result of these realities, we test for statistically significant differences in performance on a Structured Query Language (SQL) assessment to see if mode of delivery and instructor presence via synchronous online class sessions impacted student learning and performance. Given the relatively small number of students across the two course locations, we also dedicate discussion in this paper to the matter of small-n data analysis. 
REVIEW OF LITERATURE

\section{Distance Learning}

Without re-capping nearly one hundred years of distance education, we acknowledge that the field has evolved, slowly at first and then exponentially in the most recent two decades, from traditional correspondence courses to radio, televisions and satellite/closed-circuit enabled classes, to fully online, rich media enhanced academic programs at all degree levels (Sankey, 2012). The realities and deliveries of modern distance education still vary, but the cost and accessibility of Internet-based technologies, specifically broadband Internet connections even in more rural areas, along with increasingly clear and reliable two-way video conferencing systems, has helped to make current distance education offerings richer than they have ever been (Martin, Ahlgrim-Delzell, \& Budhrani, 2017). Much research has demonstrated that an online teaching environment that includes an interactive, synchronous seminar component which allows students to hear and/or see their instructor, and interact through questions and answers, polling, or other responsive activities, elevates student achievement in such classes (Annetta, Murray, Laird, Bohr, \& Park, 2008; North, 2005; Speece, 2012).

There is much assumption that synchronous sessions will always have a positive impact on student learning, although such assumptions do not always bear out (Malik, Fatima, Hussain \& Sarwar, 2017). The most likely reason for such assumptions is that synchronous instructional sessions most closely mirror the face-to-face setting found in traditional classrooms. But simply being in the same room, or online at the same time does not, in itself, ensure better knowledge transfer or comprehension (Wang \& Reeves, 2007). In order for these sessions to genuinely contribute to positive learning outcomes for students, they must minimize barriers, such as poor audio or video quality, unreliable connectivity, and, importantly, the instructor must be effective in using synchronous-enabling technologies to deliver course content (Lih-Ching Chen \& Beasley, 2006; Politis \& Politis, 2016; Wolverton, 2018).

This, and similar research, informed our first hypothesis in this study: that students who interacted in live sessions with the instructor via regular Zoom sessions would perform better on the SQL assessment. Our surprising findings run somewhat contrary to conventional wisdom, and we offer some opinion and insight into why we believe this is the case in our Discussion section below.

Additional research shows that whether or not a synchronous component is offered in an online course, students perform better when instructors take time to understand learning preferences, and to tailor curricular delivery to those preferences (Bonnici, Maatta, Klose, Julien, \& Bajjaly, 2016; Rockinson-Szapkiw, Wendt, Wighting, \& Nisbet, 2016). Students in online classes often suffer from educational deterrents which significantly impact their academic achievement, including isolation (Farooq \& Matteson, 2016), lack of motivation (Farooq \& Matteson, 2016; Tabak \& Rampal, 2014), and an inability to acquire, clarify and retain the requisite knowledge and skills to demonstrate competency in the subject matter (Rockinson-Szapkiw, Baker, Neukrug, \& Hanes, 2010). Research again supports the observation that enhancing instruction through supplemental multimedia, tutorial examples, exercises, demonstrations, etc. do make a significant difference in measures of student achievement (Roseth, Akcaoglu, \& Zellner, 2013). Such research informs our second and third hypotheses: that higher interaction with instructional materials via the Blackboard Learning Management System; and higher interaction with supplemental rich media instruction through Codecademy, will both have significant, positive effects on student performance.

\section{Small-n Research}

Our small sample size is recognized later in this paper as a potential limitation of our study. Conventional wisdom in quantitative, empirical research is that larger sample sizes yield more valid results (Paul, Clarke, Grill, \& Savitsky, n.d). While recognizing this as the norm, additional research supports the virtues and benefits of small-n research. David and Charlotte (2014) note in their research that small-n is often necessary, and in fact beneficial, when examining unique phenomena that might otherwise be masked when included as part of a much larger sample. They find that through outlier and anomaly detection, a small sample of a larger dataset may actually be extracted and examined independently, because the data in that extraction actually represent a departure from the norm; a special case or scenario that does not fit with the larger population. Such phenomena are exceptions rather than the rule, nonetheless, they are real and meaningful, especially to the subset of the population represented in such data. Our student population and teaching environment is certainly an example of such phenomena. 
Furthermore, small-n analysis has been shown to be appropriate when applied in relevant contexts (Thomann \& Manatschal, 2016). Thomann and Manatschal examine situations where cause and effect are studied. Using small-n, mixed research methods can be employed to add qualitative understanding, nuance and explanation in ways that may not be feasible or even possible with a larger sample. Tests of significance have been successfully adapted to ensure validity in such studies (Shen \& Lin, 2015). Certainly in our study, such contextualization and qualitative insight applies.

\section{RESEARCH METHODOLOGY}

Several institutions of higher learning suffered from the strong hurricane season in the Fall 2017 semester. This posed massive logistical and pedagogical problems for instructors seeking to provide continuity to students, a condition which has persisted until the time of writing. After reviewing the student outcomes from the Fall 2017 semester, the instructor decided to teach the multi-site database course in Spring 2018 in an online format with a synchronous component via Zoom. The choice aimed to increase student participation and interaction without taxing severely limited resources such as available computer lab and classroom spaces. As a result of the ongoing infrastructural, operational and organizational challenges, however, the format of the multi-site database course under review in this study was recorded differently for each section on the University's master schedule. The main campus section of the course reserved a time-slot for class meetings, while the satellite course section did not. In other words, only the main campus students knew that the course had a synchronous meeting twice a week. Not at all surprising, therefore, many students at the satellite campus booked other classes during the reserved time slot believing the course to be online and asynchronous.

Despite initial frustration and disappointment, we recognized that the differences in the schedule constituted a natural experiment. Since the time component of the schedule was essentially removed at random from one course section, we had an opportunity to explore the importance of the role of synchronous presence in the online learning environment. Building on previous work, this study seeks to learn if students with real-time online interaction with the instructor perform significantly better on an SQL assessment than students with asynchronous access to the same content via video recordings of course sessions.

In previous work, Lombardi and North (2017) and Lombardi and Holland-Minkley (2017) argued for renewed interest in techniques addressing small data for education research. Lombardi and Holland-Minkley (2017) argued for approaches to small data in education research generally as a way to improve course design and address the needs of atypical student populations. Lombardi and North (2017), on the other hand, recognized the potential for small-n data techniques while studying the problem of instructor presence in the multi-site IS classroom. This study applies permutation tests for linear models (Wheeler \& Torchiano, 2016), a technique for analyzing small sets of data, to study the role of synchronous presence in an online class of thirteen students in an undergraduate multi-site database course. In this section, we explain the rationale for the technique and its application to our research questions.

The case for permutation tests in education research at institutions like those affected by natural disaster is compelling. Dugard, File and Todman (2011) have argued convincingly for small-n experimental designs based on randomization and permutation. First, given the small size of many of our classes, standard statistical techniques for generating pvalues will fail to deliver statistically significant results. Small-n approaches based on permutation, on the other hand, can find statistically significant results with extremely low degrees of freedom. Second, permutation tests do not require the same assumptions as standard statistical approaches. For example, permutation tests do not need to make parametric assumptions regarding variables (Dugard, File \& Todman, 2011, pp. 3-4). Third, given the rapid increase in computing power, researchers and developers have created accessible software for processing permutation tests in Excel, SPSS, and R as well as other packages (Dugard, File \& Todman, 2011; Wheeler \& Torchiano, 2016). While these techniques are powerful, they do come with important limitations including a sacrifice of external validity. In other words, we cannot reliably infer anything about students as a whole based on our results. On the whole, the technique offers the opportunity to harness statistical approaches to studying our instructional choices that respond to the characteristics of our educational context and available data.

Table 1 summarizes the data collected for the study. The student information system supplied data regarding past student performance including grade point average and GPA hours. These data permit us to control for past 
performance and a student's academic maturity. We add available demographic data such as gender and location (main campus or satellite campus) to assess for potential biases in instruction. The Zoom sessions record the amount of time in minutes each student spent watching the lectures synchronously during the DB Design modules of the class and the SQL modules of the class. Similarly, we collected the amount of time spent in hours on the Blackboard course site during the DB Design modules of the class and the SQL modules of the class. The instructor assigned the Codecademy.com Learn SQL course as a reading assignment for the SQL modules of the course. We recorded the students' progress through this material at the time of the assessment. The SQL modules of the course included a project (Project 2) in which students were asked to create a database, insert data, and query the database with SQL. We record if the student submitted the project prior to the assessment date. In one case, a student had previously taken a database course. We recorded this as a flag called Prior Knowledge in our data. Some students participated in academic misconduct on the SQL exam, we recorded this with a flag as well. Finally, the SQL exam grade is the dependent variable.

Table 1. Data Collected

\begin{tabular}{|l|l|l|}
\hline Data & Variable & Description \\
\hline Student GPA & GPA & $\begin{array}{l}\text { The student's grade point average as recorded in the student } \\
\text { information system. }\end{array}$ \\
\hline GPA Hours & GPA_Hours & $\begin{array}{l}\text { The number of credit hours earned as recorded in the student } \\
\text { information system. }\end{array}$ \\
\hline Gender & Gender1 & The student's gender. \\
\hline Location & Location1 & Main Campus or Satellite location. \\
\hline $\begin{array}{l}\text { Zoom active hosts } \\
\text { (DB Design) }\end{array}$ & zoom_db & $\begin{array}{l}\text { The amount of time the student spent in Zoom sessions related to the } \\
\text { DB Design module measured in minutes. }\end{array}$ \\
\hline $\begin{array}{l}\text { Zoom active hosts } \\
\text { (SQL) }\end{array}$ & zoom_sql & $\begin{array}{l}\text { The amount of time the student spent in Zoom sessions related to the } \\
\text { SQL module measured in minutes. }\end{array}$ \\
\hline $\begin{array}{l}\text { Blackboard } \\
\text { (DB Design) }\end{array}$ & bb_db & $\begin{array}{l}\text { The amount of time the student spent in Blackboard materials related } \\
\text { to the DB Design module measured in hours. }\end{array}$ \\
\hline $\begin{array}{l}\text { Blackboard (SQL) } \\
\text { The }\end{array}$ & bb_sql & $\begin{array}{l}\text { The amount of time the student spent in Blackboard materials related } \\
\text { to the SQL module measured in hours. }\end{array}$ \\
\hline $\begin{array}{l}\text { Codecademy } \\
\text { Exercises }\end{array}$ & codecademy & The percentage of codecademy exercises completed before the exam. \\
\hline Project 2 & p21 & Did the student submit project 2 (SQL project) prior to the exam? \\
\hline Prior Knowledge & prior_knowledge1 & Did the student take a database course prior to this course? \\
\hline $\begin{array}{l}\text { Academic } \\
\text { Misconduct }\end{array}$ & am & Did the student participate in academic misconduct during the exam? \\
\hline SQL Exam Grade & exam & The dependent variable. \\
\hline
\end{tabular}

Given the experimental nature of the course design, we had many hypotheses that we wished to explore with the available data. Since we were forced to experiment with pedagogy to respond to the many constraints we experienced, we wanted to identify which factors contributed to or interfered with student learning.

The research hypotheses to be tested are as follows:

$\mathrm{H}_{1}$ : Students with more synchronous access to SQL lectures via Zoom will perform significantly better on an SQL assessment than those with less synchronous access to SQL lectures.

$\mathrm{H}_{2}$ : Students who spent more time with SQL content on Blackboard will perform significantly better on an SQL assessment than those spending less time with SQL content on Blackboard.

$\mathrm{H}_{3}$ : Students who completed more reading on Codecademy.com will perform significantly better on an SQL assessment than those completing less reading on Codecademy.com. 
To test these hypotheses we performed a linear regression with permutation in R (Wheeler \& Torchiano, 2016; R Core Team, 2017) using the variables described in Table 1 to explain student performance on an SQL assessment (SQL Exam Grade).

\section{RESULTS}

Table 2 summarizes the results of the linear regression after performing backward elimination. The backward elimination process removed the variables recording GPA hours, gender, Zoom sessions for DB Design, Prior knowledge and academic misconduct from the linear model. Based on the variables removed and the lack of significance of the Location 1 variable, we see little evidence of gender or location bias in our data. The overall model fit was statistically significant (p-value 9.371e-05) with an extremely high Adjusted R-squared (0.9772). We will assess the results from the point of view of each hypothesis below.

Table 2. Coefficients of Linear Model

\begin{tabular}{|c|c|c|c|}
\hline Variable & Coefficient Estimate & Iterations & P-Value \\
\hline GPA & 14.13 & 5000 & $0.0050 * *$ \\
\hline Location1 & 3.85 & 945 & 0.0963 \\
\hline zoom_sql & -0.04 & 5000 & $0.0128 * *$ \\
\hline bb_db & -1.67 & 5000 & $0.0020 * *$ \\
\hline bb_sql & 2.15 & 5000 & $0.0002 * * *$ \\
\hline codecademy & 0.20 & 4536 & $0.0216 *$ \\
\hline p21 & -25.56 & 5000 & $<2 \mathrm{e}-16 * * *$ \\
\hline
\end{tabular}

$\mathrm{H}_{1}$ : Students with more synchronous access to SQL lectures via Zoom will perform significantly better on an SQL assessment than those with less synchronous access to SQL lectures.

Based on our results, we have evidence that our first hypothesis was wrong. As it turns out, for every minute a student spent in a synchronous Zoom session related to SQL (zoom_sql), the student would perform worse on the SQL assessment on average. To put this in perspective, for every $\overline{7} 5$-minute synchronous lecture attended, the average student would score $(75 * 0.04=3)$ three points less on the SQL assessment. If we include all eight lectures related to SQL that counts as a 24-point loss for the average student. Suffice it to say, we will have much commentary on this surprising and humbling result in the Discussion section of this paper.

$\mathrm{H}_{2}$ : Students who spent more time with SQL content on Blackboard will perform significantly better on an SQL assessment than those spending less time with SQL content on Blackboard.

According to the results of the regression, we have evidence supporting our second hypothesis. The more time students spent working through the SQL material on Blackboard (bb_sql), the better they performed on the SQL assessment. For example, a student who spent 10 hours working on the SQL material posted to Blackboard would increase their grade by about 21 points $(10 * 2.15=21.5)$ all things being equal. Ultimately, we should not be surprised that students who spent more time studying the material performed better on the assessment.

$\mathrm{H}_{3}$ : Students who completed more reading on Codecademy.com will perform significantly better on an SQL assessment than those completing less reading on Codecademy.com. 
According to the results in Table 2, we have evidence that the Codecademy readings contributed significantly to student performance on the SQL assessment. For every additional percentage point of the readings completed, a student would on average earn additional 0.2 points on the assessment. In other words, those students completing $100 \%$ of these readings would on average earn an additional 20 points $(100 * 0.2=20)$ on the SQL assessment. Again, it is no surprise to say that students who performed the assigned readings performed better on the assessments related to those readings.

\section{DISCUSSION}

For the most part, the results of hypotheses two and three require only a modicum of discussion. The instructor chose electronic and freely available resources to decrease the cost and increase the availability of the resources to students. The challenges to the physical distribution of materials can hardly be exaggerated in a post-hurricane environment. The instructor wrote the syllabus for the database course at a time when power outages, Internet connectivity issues and transportation problems occurred frequently. The result for hypothesis one, however, demands substantial comment due to its counterintuitive nature. To reiterate the result, for every minute the average student spent in a Zoom session on SQL content, the student's grade decreased. The typical student, in other words, would have benefitted from skipping the synchronous sessions and watching them when the instructor posted them on Blackboard. We identified four potential explanations for this result: instructor inexperience, student challenges, infrastructure challenges, and course format challenges.

We cannot ignore the possibility that instructor inexperience played a part in this result. The instructor had extensive experience with Zoom prior to the delivery of the database course, but had never adapted the tool to the needs of an online course ideally taught in a computer lab. Based on the anecdotal evidence collected throughout the semester, the instructor suspected that the course format fell short of expectations. The present study confirmed those suspicions. From the pedagogical point of view, we believe that the course lacked sufficient scaffolding for the material, SQL, as well as the course format, Zoom lab sessions. For example, the syllabus defined three rather large projects spanning four to five weeks each to provide students with more time to work around their complicated schedules. While this choice responded well to the practical material constraints of limited access to electricity and Internet services, the organization of the projects produced a context in which students delayed asking for help until shortly before the due date. Falling behind and overwhelmed, some students succumbed to academic misconduct, a tell-tale sign of faulty scaffolding in a syllabus. In future iterations of the course, the instructor will err on the side of many, smaller assignments rather than larger projects. Furthermore, the instructor will provide more explicit scaffolding for the content and the format of the course.

The students also faced challenges in attempting to engage with the course. Without a physical classroom space and with reduced computer lab availability, students often logged into Zoom sessions from public or private spaces replete with distractions. The instructor often reminded students to mute their microphones when not speaking to reduce the ambient noise. The course format, therefore, may have negatively affected students living on campus more than those living at home although we do not have the data to confirm this. The students also bore the brunt of the many infrastructure challenges facing the University and the Territory. For example, several times during the Zoom sessions for SQL we lost power or Internet connectivity in the middle of the session. Students experienced frequent Internet connectivity outages which Zoom captures in its statistics. Some students logged in as many as five times during a single synchronous session to access the course meeting. Moreover, the remaining computer labs at the University do not include microphones or cameras thereby limiting student participation in the sessions. Some students did not have laptops or computers; others had laptops or computers insufficient for the needs of the course which required Access 2016 and MySQL Workbench and Server. In short, the students struggled to participate in the hands-on activities envisioned via the Zoom format due to a variety of organizational and infrastructural challenges. Finally, course format challenges contributed to the failure of the Zoom sessions. Since the course format could not function as a virtual computer lab for the reasons outlined above, Zoom sessions tended toward demonstration heavy lectures delivered to distracted students in their dorm rooms or public spaces on campus. We believe that the method and circumstances of delivery resulted in cognitive overload for students and the entirely predictable frustrations that come with it. Overall, we believe that the instability of the infrastructure compromised the pedagogical approach outlined in the course syllabus. 


\section{CONCLUSIONS}

Despite the challenges revealed in this study, we believe that this research has much to offer other educators looking for reliable ways to assess course design and student performance.

- Instructors can adapt small-n techniques to action research for course review and analysis.

- Natural experiments in educational contexts can be helpful and may sometimes be necessary.

- Synchronous, online course formats require a stable substrate of services to be successful.

- Online resources and learning materials offer good value to students even when faced with severe infrastructure challenges.

We believe that small-n techniques like those employed in this study offer excellent possibilities for those seeking to learn about their students and pedagogical effectiveness. A synchronous meeting time for an online class did not work in this context for this content. One outcome of this research is that the instructor will change the format of future courses to a hybrid model to provide a better balance of material and virtual resources. Despite the failure of the synchronous course sessions, we have ample evidence that online resources and learning materials offer good value to students even when faced with severe infrastructural and organizational challenges.

\section{Limitations}

The choice of small-n techniques necessarily sacrifices external validation. In other words, we simply cannot infer anything beyond the observed students with this particular study. Moreover, we recognize that the linear model constructed for this study is most likely overfit to the data. In order to achieve external validity with such techniques, we must replicate the experiment in other contexts (Dugard, File and Todman, 2011, pp. 134 - 135). This will be extremely difficult given the conditions that gave rise to the natural experiment providing the basis for this study. On the other hand, we can test for similar effects in future offerings of this course as a part of regular assessment activities.

We took the steps available to us to ensure high degrees of internal validity, but we believe that threats to internal validity remain in this study. Since a scheduling accident produced the conditions for this study, we have a randomly assigned treatment (reduced access to synchronous course sessions), but this condition overlaps and could possibly be confounded by location since schedules depend on location. Moreover, we took steps to ensure that the SQL assessment instruments were assigned randomly. The instructor created 24 different versions of the exam and distributed them to students with random assignment via Blackboard. Despite these efforts, threats to internal validity remain including reader bias, collinearity and confounding variables.

Despite these limitations, we believe that this approach to research has the potential to provide more information to instructors about the challenges in their classrooms.

\section{REFERENCES}

Annetta, L., Murray, M., Laird, S. G., Bohr, S., \& Park, J. (2008). Investigating student attitudes toward a synchronous, online graduate course in a multi-user virtual learning environment. Journal of Technology and Teacher Education, 16(1), 5-34.

Bonnici, L. J., Maatta, S. L., Klose, M. K., Julien, H., \& Bajjaly, S. (2016). Instructional Style and Learner-Centered Approach: A Cross-Institutional Examination of Modality Preference for Online Course Delivery in a Graduate Professional Program. Studies in Higher Education, 41(8), 1389-1407.

David, W. \& Charlotte, G. (2014). Block Randomized Trials at Places: Rethinking the Limitations of Small N Experiments. Journal of Quantitative Criminology, 1, 97.

Dugard, P \& File, P \& Todman, Jonathan. (2011). Single-case and Small-n Experimental Designs: A Practical Guide to Randomization Tests, Second Edition. 
Farooq, O., \& Matteson, M. (2016). Opportunities and Challenges for Students in an Online Seminar-Style Course in LIS Education: A Qualitative Case Study. Journal of Education for Library \& Information Science, 57(4), 271-282.

Lih-Ching Chen, W., \& Beasley, W. (2006). Integrating Instant Messenger into Online Office Hours to Enhance Synchronous Online Interaction in Teacher Education. International Journal of Instructional Media, 33(3), 277-287.

Lombardi T. \& Holland-Minkley A. (2017). Educators as Clinicians: Small Data for Education Research. In: Fee S., Holland-Minkley A., Lombardi T. (eds), New Directions for Computing Education. Springer. 277-293.

Lombardi, T. \& North, M. (2017). No Student is an Island: Degradation of Instructor Presence in the Multi-Site IS Classroom. Issues in Information Systems, 18(3), 40-52.

Malik, M., Fatima, G., Hussain Ch., A., \& Sarwar, A. (2017). E-Learning: Students' Perspectives about Asynchronous and Synchronous Resources at Higher Education Level. Bulletin of Education and Research, (2).

Martin, F., Ahlgrim-Delzell, L., \& Budhrani, K. (2017). Systematic Review of Two Decades (1995 to 2014) of Research on Synchronous Online Learning. American Journal of Distance Education, 31(1), 3-19.

North, M. A. (2005). Assessing the Value of a Synchronous Seminar Component in Online Database Classes. Issues in Information Systems, 6(1), 156-162.

Paul, C., Clarke, C. P., Grill, B., \& Savitsky, T. (n.d). Between Large-N and Small-N Analyses. Historical Methods, 46(4), 220-239.

Pike, P. D. (n.d). Improving music teaching and learning through online service: A case study of a synchronous online teaching internship. International Journal of Music Education, 35(1), 107-117.

Politis, J., \& Politis, D. (2016). The Relationship between an Online Synchronous Learning Environment and Knowledge Acquisition Skills and Traits: The Blackboard Collaborate Experience. Electronic Journal of ELearning, 14(3), 196-222.

R Core Team (2017). R: A language and environment for statistical computing. R Foundation for Statistical Computing, Vienna, Austria. URL https:/www.R-project.org/.

Rockinson-Szapkiw, A. J., Wendt, J., Wighting, M., \& Nisbet, D. (2016). The Predictive Relationship among the Community of Inquiry Framework, Perceived Learning and Online, and Graduate Students' Course Grades in Online Synchronous and Asynchronous Courses. International Review of Research in Open and Distributed Learning, 17(3), 18-35.

Rockinson-Szapkiw, A. J., Baker, J. D., Neukrug, E., \& Hanes, J. (2010). The Efficacy of Computer Mediated Communication Technologies to Augment and Support Effective Online Helping Profession Education. Journal of Technology in Human Services, 28(3), 161-177.

Roseth, C., Akcaoglu, M., \& Zellner, A. (2013). Blending Synchronous Face-to-face and Computer-Supported Cooperative Learning in a Hybrid Doctoral Seminar. Techtrends: Linking Research \& Practice to Improve Learning, 57(3), 54-59.

Sankey, M. (2012). Aligning your ducks for the student learning journey: Stories from the pond of distance ed. SITE2012.

Shen, Y., \& Lin, Z. (2015). An adaptive test for the mean vector in large-p-small-n problems. Computational Statistics and Data Analysis, 89, 25-38. 
Speece, M. (2012). Learning Style, Culture and Delivery Mode in Online Distance Education. Online Submission, $1-12$.

Tabak, F., \& Rampal, R. (2014). Synchronous E-Learning: Reflections and Design Considerations. International Journal of Education and Development Using Information and Communication Technology, 10(4), 80-92.

Thomann, E., \& Manatschal, A. (2016). Identifying Context and Cause in Small-N Settings: A Comparative Multilevel Analysis. Policy Sciences, 49(3), 335-348.

Wang, C., \& Reeves, T. C. (2007). Synchronous Online Learning Experiences: The perspectives of international students from Taiwan. Educational Media International, 44(4), 339-356.

Wheeler, B. \& Torchiano, M. (2016). lmPerm: Permutation Tests for Linear Models. R package version 2.1.0. https://CRAN.R-project.org/package=lmPerm

Wolverton, C. C. (2018). Utilizing synchronous discussions to create an engaged classroom in online executive education. International Journal of Management Education, 16, 239-244. 